\title{
EL TRABAJO DEL HOGAR EN LA PERIFERIA \\ Discriminaciones legales y estrategias de lucha
}

\author{
HOUSEHOLD WORK AT THE PERIPHERY \\ Legal discrimination and resistance
}

\author{
Manuela Fernández Bocco*
}

\begin{abstract}
RESUMEN: El objeto de estudio de la presente investigación está constituido por las discriminaciones legales sufridas por las mujeres migrantes trabajadoras del hogar en España. Específicamente, aborda las discriminaciones que resultan de la intersección entre las diferentes relaciones de poder que afectan a este sector, con la finalidad de contribuir a la visibilización de las problemáticas existentes y de las demandas respectivas. Para ello, además de los estudios disponibles, se han tomado en consideración las voces de las propias trabajadoras a partir de la observación participante en el sindicato de mujeres trabajadoras del hogar Sindihogar.
\end{abstract}

ABSTRACT: The object of study of this research paper is the legal discrimination suffered by female migrant household workers in Spain. Specifically, this paper includes the types of discrimination which result from the intersection between the different power relations that affect this sector to lay bare the existing problems and the respective demands of the part of the workers. To this end, in addition to the available studies and publications, the voices of the workers themselves have been taken into consideration based on participant observation in the labor union of household workers Sindihogar.

PALABRAS CLAVE: trabajadoras, discriminación, cuidados, Sindihogar, migrantes.

KEYWORDS: workers, discrimination, care, Sindihogar, migrants.

Fecha de recepción: 01/11/2021

Fecha de aceptación: 01/11/2021

doi: https://doi.org/10.20318/universitas.2022.6581

\footnotetext{
* Proyecto dret al Dret, Universitat de Barcelona.

E-mail: manufernandezbocco@hotmail.com
} 


\section{1.- DE CUIDADOS Y DESCUIDOS ${ }^{1}$}

Nuestras instituciones políticas y jurídicas son herederas de una tradición que concibe a las personas como individuos independientes, en cuyos proyectos de vida no hay lugar para dependencia alguna; individuos que no tienen la necesidad de ser cuidados y tampoco la responsabilidad de cuidar. Todavía hoy, y a pesar de los avances logrados gracias a los aportes de los feminismos, seguimos el camino trazado por un imaginario que entiende a los hombres como hongos ${ }^{2}$ que se reproducen sin más, que mágicamente llegan a la edad adulta y que, en apariencia, jamás llegarán a la ancianidad.

A decir verdad, en la tradición moderna los hombres han sido representados como independientes porque la gestión de sus necesidades ha sido desplazada hacia las mujeres. Como bien expuso Carole Pateman, la circunscripción de las mismas en una esfera privada $^{3}$ constituyó la condición de posibilidad del surgimiento de la prestigiosa esfera pública, espacio ocupado por varones independientes que deciden sobre el interés general. Esto explica la dificultad que presenta, aún hasta nuestros días, la consideración como una res publica de la necesidad de cuidados, relegada a esa esfera privada donde madres, abuelas, hijas y trabajadoras del hogar contratadas, ${ }^{4}$ en su rol de gestoras de dependencias, ${ }^{5}$ dedican sus horas a satisfacer esas necesidades tan humanamente elementales como políticamente olvidadas.

Hace más de seis décadas que las críticas feministas vienen subrayando la importancia del trabajo en el ámbito del hogar. Y es indudable que, con los años y con las luchas, se ha avanzado mucho en este aspecto: las labores del hogar han sido reconocidas como un trabajo por la legislación -al menos cuando se trata de servicios prestados por personas externas a la familia a cambio de una remuneración- $y$, con posterioridad, se han ido estableciendo mejoras en las condiciones laborales. ${ }^{6}$

\footnotetext{
${ }^{1}$ Expresión tomada del libro homónimo Viviana Osorio Pérez (ed) De cuidados y descuidos. La economía del cuidado en Colombia y perspectivas de política pública (Escuela Nacional Sindical, 2015).

2 Se hace referencia a la crítica que realiza Pateman respecto a la tesis de Hobbes. Al respecto ver Carole Pateman, El contrato sexual (Anthropos, 1995).

${ }^{3}$ Ibid, En Pateman la figura de la esfera privada aparece identificada con la esfera doméstica, en contraposición a la esfera pública, identificada con el ámbito estatal y civil.

${ }^{4}$ Debido a que la presencia de mujeres en el sector es cuantitativa y cualitativamente más relevante, y con el objetivo de subrayar tal circunstancia, se utiliza el femenino. No obstante, la presencia de varones debería aumentar: se trata de una revolución pendiente, igualmente necesaria en términos de empleo, de cubrir la necesidad social que se viene comentando y de ruptura con los roles sexistas que atraviesan la actual división del trabajo.

${ }^{5}$ Blanca Rodríguez Ruiz, 'Hacia un estado post-patriarcal. Feminismo y cuidadanía' (2010) 149, Revista de Estudios Políticos nueva época, 87, 96.

6 En España, y después de varios intentos en esta dirección, el Real Decreto 1424/1985, de 1 de agosto, puso fin a la jurisdicción meramente civil del sector,
} 
Sin embargo, como se argumenta más adelante, los trabajos que tienen lugar en el espacio doméstico siguen portando la etiqueta que los clasifica como tareas privadas y sin mayor importancia social; lo cual es coherente con la falta de reconocimiento que padecen las personas que se dedican a cuidar y a sostener el hogar. Pues el mito de la autosuficiencia «que se basa en ocultar las dependencias y a los sujetos que las resuelven ${ }^{7}$ parece seguir vigente todavía hoy.

Ahora bien, referirse a las relaciones de poder patriarcales como las únicas que atraviesan el ámbito del hogar implicaría caer en un grave reduccionismo. En España, por ejemplo, la actividad legislativa de los últimos años ha seguido esta lógica simplista: se ha ignorado y hasta se ha fortalecido- ${ }^{8}$ el entramado relacional jerárquico en el que se inscriben dichas actividades, pues se ha desestimado el hecho de que sean mayormente mujeres migrantes las que en la actualidad sostienen la dependencia y los hogares de la población española.

Al respecto, las últimas estadísticas muestran que las mujeres extranjeras están sobrerrepresentadas en el servicio formal del hogar familiar: mientras que éstas representan menos del $6 \%$ de la población española, ocupan casi la mitad del sector. ${ }^{9}$ De otro lado, del total de autorizaciones de trabajo concedidas a mujeres migrantes en lo que va del 2021 , el $55 \%$ han sido otorgadas para trabajar en el hogar. ${ }^{10}$ Asimismo, es lógico pensar que la proporción de extranjeras empleadas

regulándolo como una «relación laboral de carácter especial»; no obstante, las trabajadoras del hogar quedaron igualmente en una situación de infraprotección, tanto a nivel laboral como de seguridad social. Tuvieron que pasar más de 25 años para la próxima legislación específica. Así, el Real Decreto 1620/2011, de 14 de noviembre, introduce mejoras en materia de contratación, vacaciones, etc., y en virtud de la ley 27/2011 de 1 de agosto, se integra el Régimen Especial de Empleados del Hogar en el Régimen General de la Seguridad Social como un sistema especial.

7 Amaia Pérez Orozco, Subversión feminista de la economía. Aportes para un debate sobre el conflicto capital-vida (4a ed, Traficantes de sueños, 2019) 224.

8 En relación a ello, se ha señalado que la Ley Orgánica 3/2007, de 22 de marzo, para la igualdad efectiva de mujeres y hombres, al no cuestionar el mito de la independencia, «obliga a las mujeres a desplazar (parte de) la gestión de la dependencia hacia otros colectivos, normalmente también de mujeres» generándose nuevas relaciones de poder. Ver Blanca Rodríguez Ruiz, 'Hacia un estado postpatriarcal. Feminismo y cuidadanía' (2010) 149, Revista de Estudios Políticos nueva época, 87, 107. En el mismo sentido, se ha sostenido que «si miramos de cerca la ley, ésta no incluye ninguna medida específica (ningún deber) para evitar la discriminación múltiple que padecen las mujeres extranjeras en relación a sus pares varones, a los hombres españoles, o a las propias mujeres europeas». Ver Antonio Giménez Merino, 'Reconocer diferencias atribuyendo derechos' en José A. Estévez Araújo (ed) El libro de los deberes. Las debilidades e insuficiencias de la estrategia de los derechos (Trotta, 2013) 123.

${ }^{9}$ Si se tienen en cuenta las personas de entre 20 y 45 años, las extranjeras llegan a sumar el $65 \%$. Ver 'Afiliados a fin de mes, por edad, género, régimen y nacionalidad' (Tesorería General de la Seguridad Social, abril de 2021) <https://w6.segsocial.es/PXWeb/pxweb/es/> última consulta en abril de 2021.

10 'Estadística de autorizaciones de trabajo a extranjeros' (Subdirección Nacional de Estadística y Análisis Sociolaboral, mayo de 2021) <https://www.mites.gob.es/estadisticas/pte/welcome.htm> última consulta el 13 de junio de 2021. 
en el sector aumenta en la franja de trabajadoras informales, habida cuenta de que dicho ámbito laboral constituye para las mujeres en situación irregular un refugio habitual y para las familias españolas un modo de abaratar los servicios relacionados con la limpieza del hogar y el cuidado de personas.

Es sabido que, desde hace algunas décadas, la sociedad española ha experimentado un aumento en la demanda de cuidados. Desde la economía feminista se indican tres factores que han contribuido en este sentido: en primer lugar, se destaca el envejecimiento de la población, habida cuenta de que, desde 1975 hasta la fecha, la esperanza de vida se ha incrementado en más de 10 años $^{11}$ y el porcentaje de población de personas mayores de 80 , colectivo especialmente vulnerable, está cerca de cuadruplicarse. ${ }^{12}$ El segundo factor está constituido por los cambios en las unidades domésticas, específicamente por el aumento de familias monoparentales, circunstancia que ha contribuido a modificar la organización del trabajo en el hogar. ${ }^{13}$ Por último, se destaca el incremento en el acceso de mujeres al mercado de trabajo, ya que desde los años 80 el porcentaje de mujeres en activo ha pasado de un $27,10 \%$ a un $53,03 \% .{ }^{14}$

Frente a estos cambios sociales, los hombres, los mercados y el Estado no han respondido de manera satisfactoria; pues los cuidados continúan, en gran medida, resolviéndose en el interior de los domicilios particulares. En consecuencia, al día de hoy, la crisis de los cuidados está siendo paliada por mujeres en situación de precariedad, en su mayoría provenientes de países del sur. ${ }^{15}$

11 'Esperanza de vida al nacimiento según sexo' (Instituto Nacional de Estadísticas, 1975, 2019) <https://www.ine.es/jaxiT3/Tabla.htm?t=1414> última consulta el 7 de agosto de 2020.

12 'Proporción de personas mayores de cierta edad' (Instituto Nacional de Estadísticas, 1975, 2020) <https://www.ine.es/jaxiT3/Tabla.htm?t=1417\&L=0> última consulta el 7 agosto de 2020.

${ }^{13} \mathrm{El} 80 \%$ de los progenitores en familia monoparentales son mujeres. En este punto, interesa poner de relieve la dificultad que implica en estos casos conciliar los cuidados y la actividad generadora de ingresos, lo cual puede producir una sobrecarga de trabajo perjudicial para la salud física y mental. Ver 'Número de hogares monoparentales según sexo, edad y estado civil del progenitor' (Instituto Nacional de Estadística, 2019) $<$ https://www.ine.es/jaxi/Tabla.htm?path=/t20/p274/serie/prov/p01/l0/\&file $=0101$ 7.px\&L=0 > última consulta el 7 de agosto de 2020 .

14 'Tasas de actividad por distintos grupos de edad, sexo y comunidad autónoma' (Instituto Nacional de Estadística, 1980, 2020)

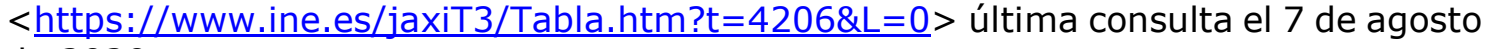
de 2020.

15 Sobre esta temática se puede consultar Amaia Pérez Orozco, Perspectivas feministas en torno a la economía: el caso de los cuidados (Consejo Económico y Social 2006); Amaia Pérez Orozco y Silvia López Gil, Desigualdades a flor de piel: Cadenas globales de cuidados (ONU mujeres 2011); Sandra Ezquerra, 'Crisis de los cuidados y crisis sistémica: la reproducción como pilar de la economía llamada real' (2011) 2 Investigaciones Feministas 175; Sira del Río, 'La crisis de los cuidados: precariedad a flor de piel' (2004) CGT Comisión Confederal contra la Precariedad 1. 
En este sentido, parece razonable afirmar que la lucha por la emancipación femenina, al hacer abstracción del sistema capitalista y del racismo estructural, ha terminado por constituir una gran paradoja: algunas mujeres han podido salir de la esfera doméstica, pero a costa del trabajo precario de muchas otras.

En España, las trabajadoras que son contratadas para realizar tareas de limpieza o de cuidados en un hogar particular ${ }^{16}$ se encuentran en una situación de gran precariedad. Pues se trata de un sector que la misma letra de la ley considera «especial» y, por esta razón, aquellas gozan de menos derechos que trabajadores y trabajadoras de cualquier otro ámbito laboral: no tienen reconocido el derecho al paro; no están protegidas por la legislación sobre prevención de riesgos de trabajo; pueden ser despedidas sin causa alguna y sin percibir la indemnización correspondiente a un despido común bajo la figura del desistimiento del empleador; no cotizan por salarios reales y no se integran las lagunas de cotización en el cálculo de pensiones. Además, no tienen garantizados los derechos reconocidos por falta de controles eficaces.

Asimismo, se estima que un importante porcentaje de trabajadoras están ejerciendo la actividad en la economía sumergida, ${ }^{17}$ sin protección de ningún tipo, por «encontrarse irregularmente en territorio español». 18

La pandemia del COVID-19 puso de manifiesto, una vez más, la marginalidad de las personas sin papeles. En el año 2020, cuando se decretó por primera vez el confinamiento, el gobierno español tomó diversas medidas, aunque prácticamente ninguna consideraba a dichos colectivos. ${ }^{19}$ Cobrar por hora, en la informalidad, significa que si no se

${ }^{16}$ A los fines analíticos, en este artículo se acepta la definición de trabajo de hogar expresada en el artículo 1.4 del Real Decreto 1620/2011.

$17 \mathrm{Si}$ se considera la diferencia entre los datos publicados por el Instituto Nacional de Estadística sobre personas ocupadas en el trabajo de hogar y los relativos a las afiliaciones de la Seguridad Social, las trabajadoras que actualmente se encuentran ejerciendo la actividad en la economía sumergida son aproximadamente 200.000; esto es, un tercio del sector. Al respecto ver 'Afiliados a fin de mes, por edad, género, régimen y nacionalidad' (Tesorería General de la Seguridad Social, abril de 2021) <https://w6.seg-social.es/PXWeb/pxweb/es/> última consulta el 22 de abril de 2021 y 'Ocupados por sexo y rama de actividad. Valores absolutos y porcentajes respecto del total de cada sexo' (Instituto Nacional de Estadística, septiembre de 2021) $<$ https://www.ine.es/jaxiT3/Tabla.htm?t=4128 $>$ última consulta el 23 de noviembre de 2021.

18 La Ley Orgánica 4/2000, de 11 de enero, sobre derechos y libertades de los extranjeros en España y su integración social, utiliza esta expresión en su artículo 53 al enumerar las infracciones graves.

${ }^{19}$ A nivel estatal se aprobó el Real Decreto-ley 13/2020, de 7 de abril, por el que se adoptan determinadas medidas urgentes en materia de empleo agrario. Mediante este decreto, ante la falta de trabajadores y trabajadoras en el sector agrario, se flexibilizaron las contrataciones de (algunas) personas sin permiso de trabajo. Esta disposición ha sido considerada una burla por diversos colectivos, por reconocer parcialmente la población migrante, solo con fines utilitaristas, en un contexto de emergencia. Ver 'Respecto al Real Decreto-ley 13/2020, de 7 de abril, por el que se adoptan determinadas medidas urgentes en materia de empleo agrario' (Sindihogar, 
trabaja, no se come. En esta situación se han encontrado, desde entonces, muchas mujeres, resistiendo gracias a las redes solidarias que se tejen entre quienes quedan al margen del sistema legal. En otros casos, en los periodos de confinamiento estricto, muchas trabajadoras internas han debido seguir prestando servicios, a veces en condiciones de insalubridad y sin posibilidad de salir de sus centros de trabajo.

Actualmente, las trabajadoras del hogar, especialmente las cuidadoras, continúan realizando una labor de gran importancia social, cuyo valor se intensifica en los tiempos que corren. Por esta razón, parece pertinente hablar de marginalidad en lugar de exclusión: pues ellas están presentes; incluirlas es una necesidad social -aunque en un margen, en la oscuridad, para que sigan trabajando sin que nadie las vea-.

Hace nueve años que Sindihogar viene denunciando esta violencia institucional que oprime a las trabajadoras del sector. Conformado en su mayoría por mujeres migrantes de más de 15 países extracomunitarios, Sindihogar se consagró en el año 2011, en Barcelona, como el primer sindicato independiente de mujeres trabajadoras del hogar en España. Su organización es autogestionaria y su estructura horizontal; se trata de un espacio de asunción de deberes recíprocos, cuyo objetivo es paliar la discriminación mediante la lucha, el acompañamiento y los cuidados mutuos. Esta investigación es, en gran medida, fruto del trabajo realizado en el sindicato a lo largo de un año.

Las activistas de Sindihogar sostienen que el desdén sistemático que al respecto manifiesta la clase política constituiría una muestra clara de la connivencia con la invisibilización de la (inter)dependencia humana, al reducir los cuidados y los diversos trabajos del hogar a meros problemas de mujeres que deben ser resueltos en la intimidad de la esfera privada. ${ }^{20}$ En otras palabras, denuncian la hipocresía implícita en el hecho de negar la importancia de dichas tareas y la necesidad de personas que las realicen, a la vez que se desplaza la carga hacia las mujeres migrantes, convertidas en un paliativo espontáneo y barato a la crisis de los cuidados.

abril de 2020) <https://sindillar.org/comunicado-30-de-marzo-dia-internacional-delas-trabajadoras-de-hogar/> última consulta el 23 de noviembre de 2021 . A nivel autonómico, a través del Decret Llei 25/2020, de 16 de juny, se tomaron algunas medidas en relación a las cuidadoras sin papeles.

20 Podría decirse que la llamada Ley de Dependencia ha incorporado una respuesta (parcial, insuficiente) a la necesidad de cuidados. La misma presenta grandes limitaciones en diversos aspectos: tiene un ámbito de protección demasiado restringido (no cubre, por ejemplo, la atención a las infancias o las dependencias transitorias); las prestaciones otorgadas son a todas luces insuficientes para las atenciones requeridas (Olga Abasolo, 'El debate feminista en torno al concepto de cuidados' [2010] 10 CIP-Ecosocial Boletín ECOS 1); y, además, no se ha indagado lo suficiente sobre la situación de las personas cuidadoras (mujeres, migrantes, sin papeles), haciendo abstracción de esta realidad. 


\section{2.- LA NORMATIVA SOBRE EXTRANJERÍA: UNA CARRERA DE OBSTÁCULOS PARA LAS MUJERES MIGRANTES}

Desde hace más de tres décadas, específicamente a partir de la firma del acuerdo de Schengen, ${ }^{21}$ las distintas legislaciones en materia de extranjería se han instituido como poderosas herramientas de vigilancia y de marginación social.

En España, los excesivos controles fronterizos, los obstáculos legales impuestos para residir y trabajar en el país y las redadas policiales en barrios habitados mayormente por migrantes dan cuenta de lo que aquí se afirma. ${ }^{22}$ En cuanto a esta última práctica, cabe mencionar que el control de identidad a personas extranjeras está permitido por ley ${ }^{23}$ y que el Tribunal Constitucional ha entendido que es posible tener en cuenta rasgos étnicos o raciales para llevar a cabo estas identificaciones:

[...] cuando los controles policiales sirven a tal finalidad, determinadas características físicas o étnicas pueden ser tomadas en consideración en ellos como razonablemente indiciarias del origen no nacional de la persona que las reúne. ${ }^{24}$

Probablemente, la forma más extrema de discriminación institucionalizada de estos colectivos sean los Centros de internamiento de extranjeros (CIE), verdaderas cárceles administrativas para personas migrantes cuya única falta es habitar un territorio sin el permiso pertinente. ${ }^{25}$

Sin embargo, las mencionadas políticas de cierre no han cumplido con la pretendida función de restringir o evitar el fenómeno migratorio. 26 Pues, lejos de ello, estos movimientos se han acrecentado, y los abusos y las restricciones en el reconocimiento de derechos han terminado por consolidar un status diferenciado que reduce a muchos colectivos migrantes a una condición de inferioridad:

Pensar que la despersonalización de determinadas categorías de seres humanos es imposible en nuestra sociedad humanista y racional

${ }^{21}$ El Acuerdo fue firmado en Schengen, Luxemburgo, en 1985. En virtud del mismo, «varios países de Europa suprimieron los controles en las fronteras interiores (entre esos países) y trasladaron esos controles a las fronteras exteriores (con terceros países) [...]. Los países participantes aplican normas comunes para controlar las fronteras exteriores y también en materia de visados y de cooperación entre los servicios policiales y judiciales en el ámbito penal». Ver 'Acuerdo Schengen' (Ministerio del Interior) <http://www.interior.gob.es/web/servicios-alciudadano/extranjeria/acuerdo-de-schengen> última consulta el 23 de noviembre de 2021.

${ }^{22}$ Eduardo Melero Alonso, 'Las identificaciones policiales con perfil racial o étnico como instrumento de control migratorio: derecho administrativo del enemigo' (2018) 193, Revista Española de Derecho Administrativo, 243.

${ }^{23}$ Ley Orgánica 4/2015, de 30 de marzo, de protección de la seguridad ciudadana, artículo 13.

24 Sentencia 13/2001 (2001) AN Sala de lo contencioso-administrativo.

${ }^{25}$ Héctor Silveira Gorski, 'Biopolítica de Estados expulsores' (2012) 49, Política y Sociedad, 497.

${ }^{26}$ Luigi Ferrajoli, Manifiesto por la igualdad (Trotta, 2019). 
es una ilusión peligrosa (cuando no efecto de una verdadera y propia eliminación histórica). Los procesos jurídico-políticos que la permiten son varios y difusos, pero pueden ser reconducidos a un denominador común: la constitución de un doble régimen jurídico para quien está incluido y quien está excluido. ${ }^{27}$

En este sentido, interesa señalar algunos aspectos del régimen jurídico de las personas migrantes en España, específicamente las posibilidades de entrar en el territorio con visados para residir y trabajar, así como las opciones disponibles para obtener la autorización respectiva una vez que se han cruzado las fronteras. Se señalan especialmente las consecuencias que todos estos procesos acarrean en las vidas de las mujeres migrantes.

Los requisitos de entrada, permanencia y salida del territorio español están regulados por la Ley Orgánica 4/2000, de 11 de enero, sobre derechos y libertades de los extranjeros en España y su integración social (en adelante, LOE) y por el reglamento respectivo aprobado por el Real Decreto 557/2011, de 20 de abril (en adelante, RLOE). Estos cuerpos normativos detallan la carrera de obstáculos ${ }^{28}$ que las personas migrantes deben superar para ser reconocidas, finalmente, como sujeto de derechos.

\section{1- Cruzar las fronteras}

En concordancia con lo estipulado en el acuerdo de Schengen, el artículo 4 del RLOE establece que aquellas personas que deseen viajar hacia España deben contar con pasaporte, visado y una serie de documentos que justifiquen el objeto y las condiciones de entrada y estancia; acreditar medios económicos suficientes o estar en condiciones de obtenerlos - tanto para permanecer en el país como para retornar-; presentar un certificado sanitario en los casos en que se estipule; no tener prohibida la entrada a España y no suponer un peligro para la salud pública, el orden público, la seguridad nacional o las relaciones internacionales.

Una vez en el país, las personas extranjeras pueden encontrarse en situación de estancia ${ }^{29}$ o en situación de residencia ${ }^{30}$. En el primer caso, están habilitadas para permanecer en el territorio por un plazo máximo de tres meses en un periodo de seis; en el segundo, pueden permanecer por un tiempo superior. ${ }^{31}$

27 Alessandro Dal Lago, 'Personas y no-personas' en Héctor Silvera (ed) Identidades comunitarias y democracia (Trotta, 2000) 137.

${ }^{28}$ Expresión utilizada en el marco de Sindihogar para referir a las distintas etapas y exigencias en torno al trámite de regularización administrativa.

29 Real Decreto 557/2011, de 20 de abril, por el que se aprueba el Reglamento de la Ley Orgánica 4/2000, sobre derechos y libertades de los extranjeros en España y su integración social, artículo 30.

${ }^{30}$ Ibid artículo 30 bis.

31 Las personas residentes, a su vez, pueden estar en situación de residencia temporal, esto es, habilitadas para permanecer en el país hasta 5 años (Ley Orgánica 4/2000, sobre derechos y libertades de los extranjeros en España y su integración 
Si se atiende a la normativa, quienes entran en España con la intención de quedarse por más de 90 días para realizar una actividad laboral deben contar con un visado de residencia y trabajo ${ }^{32}$. Y el primer requisito para solicitarlo consiste en ser titular de la autorización inicial pertinente ${ }^{33}$. Ahora bien, las condiciones exigidas para obtener tal autorización parecen imposibles de cumplimentar por parte de estas mujeres. En lo que sigue se verá por qué.

La autorización puede ser solicitada para trabajar por cuenta propia o por cuenta ajena. 34 En ambos casos es imprescindible satisfacer los requisitos generales relativos a la residencia regulados en el artículo 105.2 del RLOE: no encontrarse irregularmente en el país; carecer de antecedentes penales; no figurar como rechazable en el territorio de países con los que España tenga un acuerdo al respecto; que, en su caso, haya transcurrido el plazo de compromiso de no regreso a territorio español; y haber abonado las tasas correspondientes.

Además de estas condiciones, para obtener un permiso para trabajar por cuenta propia el art. 105.3 RLOE impone, entre otros requisitos, «acreditar que la inversión prevista para la implantación del proyecto sea suficiente y su eventual incidencia en la creación de empleo» y que «el extranjero cuente con recursos económicos suficientes para su manutención y alojamiento». Contar con el dinero necesario para invertir en la creación de una empresa (y para poder vivir cómodamente mientras tanto) constituye una exigencia cuyo cumplimiento está fuera del alcance de la mayor parte de las personas migrantes. Las estadísticas de autorizaciones de trabajo a extranjeros dan cuenta de ello: durante el año pasado, del total de permisos otorgados, apenas un 2,7\% fueron concedidos para trabajar por cuenta propia. ${ }^{35}$

Si se quiere entrar en el país con un visado para trabajar por cuenta ajena los obstáculos no son menores. Según el artículo 64 del RLOE, para solicitar la autorización respectiva es necesario que «la situación nacional de empleo permita la contratación del trabajador

social, artículo 31); o bien en situación de residencia de larga duración, pudiendo permanecer de manera indefinida en las mismas condiciones que las personas españolas (ibid artículo 32).

32 Real Decreto 557/2011, de 20 de abril, por el que se aprueba el Reglamento de la Ley Orgánica 4/2000, sobre derechos y libertades de los extranjeros en España y su integración social, artículo 25.

33 Ibid artículos 70 y 108.

${ }^{34}$ EI RLOE regula otras posibilidades, como el caso de la reagrupación familiar (capítulo II). Sin embargo, como la mayoría de las mujeres que forman parte de esta investigación han viajado solas, se prescinde del análisis de esta vía. Asimismo, cabe aclarar que las autorizaciones reguladas en los capítulos $\mathrm{V}$ (profesionales altamente cualificados) y VI (de duración determinada) son modalidades de la autorización de trabajo por cuenta ajena, por lo cual se considera innecesario tratarles por separado. 35 'Estadísticas de autorizaciones de trabajo a extranjeros' (Subdirección Nacional de Estadística y Análisis Sociolaboral, mayo de 2021) <https://www.mites.gob.es/estadisticas/pte/welcome.htm> última consulta el 23 de junio de 2021. 
extranjero». Este requisito prácticamente imposibilita conseguir dicha autorización. La situación nacional de empleo permite la contratación de la persona extranjera si el trabajo a realizar está incluido en el catálogo de ocupaciones de difícil cobertura, o bien cuando a partir de la gestión de la oferta de empleo se concluya la insuficiencia de demandantes adecuados. ${ }^{36}$ Dicho catálogo es publicado de manera trimestral por el Servicio Público de Empleo Estatal. En el cuarto trimestre del 2021, las ocupaciones de difícil cobertura se han circunscrito a deportistas profesionales, entrenadores deportivos y trabajadores navales. ${ }^{37}$

Frente a las escasas y exigentes opciones disponibles en la legislación española, las mujeres que migran hacia España con pocos recursos y con el innegociable objetivo de trabajar tienen dos alternativas: entrar con un visado de estancia y permanecer de manera irregular una vez pasados los 90 días, o bien intentarlo por puestos no habilitados. 38

\section{2.- Residir y trabajar en España}

Una vez que se ha entrado en el país, las posibilidades de regularización están dadas por las circunstancias excepcionales reguladas en el título $V$ del RLOE: por arraigo, protección internacional, razones humanitarias, colaboración con autoridades, seguridad nacional o interés público (capítulo I); por ser mujer víctima de violencia de género (capítulo II); por colaboración contra redes organizadas (capítulo III); y por ser extranjero víctima de trata de seres humanos (capítulo IV). ${ }^{39}$

Durante el trabajo de campo realizado en Sindihogar no se ha tenido contacto con ningún caso de regularización administrativa por

\footnotetext{
${ }^{36}$ Cabe aclarar que no se tendrá en cuenta la situación nacional de empleo cuando la autorización vaya dirigida a nacionales de Chile y Perú, por tratarse de Estados suscriptores de acuerdos con España; y tampoco cuando la persona solicitante se encuentre entre los supuestos recogidos en el artículo 40 de la LOE. Sin embargo, estos supuestos constituyen excepciones a la regla.

37 'Catálogo completo de ocupaciones de difícil cobertura' (SEPE, 2021) $<$ https://www.sepe.es/HomeSepe/empresas/informacion-para-

empresas/profesiones-de-dificil-cobertura/profesiones-mas-demandadas.html> última consulta el 23 de noviembre de 2021.

38 Tamara González Fernández, 'La discriminación múltiple de las trabajadoras sexuales extranjeras en España' (Dipòsit Digital de la Universitat de Barcelona, 2019) <http://diposit.ub.edu/dspace/handle/2445/1201> última consulta el 23 de noviembre de 2021.

${ }^{39} \mathrm{Al}$ respecto, interesa mencionar que existe la posibilidad de obtener la residencia a partir del matrimonio o la pareja de hecho con una persona ciudadana comunitaria, pero que, sin embargo, se trata de casos particulares que no reflejan una práctica usual entre las trabajadoras.
} 
vía distinta al arraigo. ${ }^{40}$ Además, Norma Falconi, asesora en extranjería, asegura que estas regularizaciones constituyen, en la práctica, casos inusuales. Por esta razón, se analiza aquí la figura del arraigo, prescindiendo del estudio de las demás circunstancias excepcionales mencionadas, habida cuenta de que no componen vías normalmente accesibles para las mujeres participantes en esta investigación. 41

Existen tres tipos de arraigo regulados en el RLOE: el familiar, el laboral y el social. El primero exige ser padre o madre de menor con nacionalidad española, o bien ser hija o hijo de madre o padre que hubiera tenido originariamente dicha nacionalidad ${ }^{42}$. Si se tiene en cuenta que ésta no se obtiene por el hecho de nacer en el territorio respectivo, resulta obvio que la vía del arraigo familiar no es accesible para estas mujeres, salvo excepciones.

El arraigo laboral es una opción un poco más viable. EI RLOE requiere acreditar la permanencia continuada en el país durante un periodo mínimo de dos años, carecer de antecedentes penales en España y en el país de origen o en el que se haya residido durante los últimos cinco años, y demostrar la existencia de relaciones laborales cuya duración sea de al menos seis meses mediante resolución judicial o administrativa. 43 Para obtener este documento probatorio, sin embargo, es necesario iniciar un proceso que no todas las personas están dispuestas a transitar; pues demandar en sede judicial a la parte empleadora o denunciarla ante la Inspección de Trabajo no siempre se presenta como una opción deseable, y además estos procedimientos exigen un gasto de tiempo, de energía y de otros recursos que muchas personas prefieren evitar.

En marzo de 2021 el Tribunal Supremo, mediante sentencia $1184 / 2021$, se pronunció favorablemente sobre la posibilidad de solicitar el arraigo laboral presentando como medio de prueba un informe de vida laboral. Esta posibilidad abriría las puertas a muchas personas migrantes en situación de irregularidad sobrevenida. No obstante, se trata de una vía aún embrionaria, y que, según se ha establecido con posterioridad, favorecería sólo a quienes hayan

\footnotetext{
40 Entre mujeres de determinadas nacionalidades, solicitar asilo constituye una práctica más o menos común. Sin embargo, en todos los casos con los cuales se ha tenido contacto, las respuestas han sido negativas.

${ }^{41}$ En este sentido, se ha señalado que «Todas las circunstancias excepcionales requieren o bien la colaboración con la autoridad administrativa, policial, fiscal o judicial (a riesgo de ser sancionado por encontrarse en situación irregular), o bien haber sido víctima de un delito de violencia de género o de los delitos [...] contra los derechos de los trabajadores del Código Penal, con resolución judicial donde se declare la condición de víctima, o bien ser solicitante de asilo o persona desplazada». Se trata, entonces, de vías de regularización cuyos requisitos son más complejos y exigentes, y por ende menos accesibles (Ibid 30).

42 Real Decreto 557/2011, de 20 de abril, por el que se aprueba el Reglamento de la Ley Orgánica 4/2000, sobre derechos y libertades de los extranjeros en España y su integración social, artículo 124.3.

43 Ibid artículo 124.1.
} 
trabajado de manera regular en los dos años inmediatamente anteriores a la presentación de la solicitud, con una jornada semanal mínima de 30 horas y durante 6 meses. 44

La tercera vía, como se ha adelantado, es el arraigo social. Interesa detenerse aquí por tratarse de la opción más corriente:

Por arraigo social, podrán obtener una autorización los extranjeros que acrediten la permanencia continuada en España durante un periodo mínimo de tres años.

Además, deberá cumplir, de forma acumulativa, los siguientes requisitos:

a) Carecer de antecedentes penales en España y en su país de origen o en el país o países en que haya residido durante los últimos cinco años.

b) Contar con un contrato de trabajo firmado por el trabajador y el empresario en el momento de la solicitud para un periodo que no sea inferior a un año. Dicha contratación habrá de estar basada en la existencia de un solo contrato, salvo en los siguientes supuestos:

1. 0 En el caso del sector agrario, cabrá la presentación de dos contratos, con distintos empleadores y concatenados, cada uno de ellos de duración mínima de seis meses.

2.0 En el caso de desarrollo de actividades en una misma ocupación, trabajando parcialmente y de manera simultánea para más de un empleador, se admitirá la presentación de varios contratos, todos ellos de duración mínima de un año, y cuya suma debe representar una jornada semanal no inferior a treinta horas en el cómputo global. 45

En general, las personas que entran en territorio español sin un visado de residencia y trabajo tienen plena consciencia de que el proceso para obtener los papeles no resulta fácil ni rápido.

El primer requisito exigido es la permanencia continuada en el territorio durante tres años como mínimo, lo cual conlleva algunas dificultades implícitas. Pues, en pocas (y paradójicas) palabras, la ley establece la obligación de vivir en una situación de infracción permanente durante esos años como condición para obtener el permiso de residencia y trabajo. Las autoridades parecen decir: no deberías estar aquí, pero si soportas tres años, quizás puedas quedarte. Este requisito implica que, durante ese período, las personas migrantes deban trabajar en la economía sumergida, sin ninguna protección social, a cambio de salarios irrisorios y con el miedo lógico de ser objeto de un expediente de expulsión.

\footnotetext{
44 Eduardo Rojo Torrecilla, 'Ampliación de la posibilidad de solicitar la autorización de residencia por arraigo laboral' (2021) 5/2021 Revista de Jurisprudencia Laboral 7. 45 Real Decreto 557/2011, de 20 de abril, por el que se aprueba el Reglamento de la Ley Orgánica 4/2000, sobre derechos y libertades de los extranjeros en España y su integración social, artículo 124.2.
} 
Además, la permanencia continuada en España debe ser demostrada, preferentemente, mediante el padrón. ${ }^{46}$ Conseguirlo no es un tema menor. De más está señalar que los elevados precios de los alquileres y las exigencias en torno a las garantías impiden que la mayoría de las personas migrantes y la totalidad de las sin papeles puedan acceder a una vivienda:

Especialmente difícil es el acceso al alojamiento digno de personas extranjeras en situación administrativa irregular. La urgencia por encontrar un lugar en el que vivir que sufren las personas recién llegadas unida a su situación particular de «sin papeles», que no les permite acceder a un contrato laboral formal ni, por tanto, pueden certificar sus ingresos a través de una nómina, así como la existencia de perjuicios xenófobos de muchos de los arrendadores hacen que en muchos casos estas personas se vean forzadas a aceptar cualquier condición y precio o a buscar estrategias alternativas de vivienda. ${ }^{47}$

La alternativa más corriente, en especial cuando se trata de mujeres solas, es acudir a la renta de una habitación en viviendas habitadas por otras personas en similares condiciones. $Y$ aquí es cuando surge el problema, porque la persona arrendadora puede exponer diversos motivos para negar el padrón, como por ejemplo la pérdida de una ayuda pública. El negocio en torno a esto probablemente constituye una prueba de las dificultades que se presentan; pues es de sobra conocida la existencia de «ventas» de padrón, así como los problemas que ello acarrea:

El problema no es que te cobren por empadronarte, el problema es que te dan de baja a los dos meses. Y cuando las personas piden el padrón histórico para solicitar el arraigo social, se encuentran con que durante los últimos años no estuvieron empadronadas. ${ }^{48}$

Además de constituir un medio de prueba, el padrón también es la condición de posibilidad para gozar de ciertos derechos fundamentales, tales como el acceso a la salud. Por todas estas razones, hace varios años, en Cataluña, distintas asociaciones de migrantes comenzaron a exigir de manera organizada y colectiva el acceso al padrón sin domicilio fijo. En Barcelona es posible utilizar esta vía desde hace cinco años; ${ }^{49}$ sin embargo, en las demás ciudades de la Cataluña esta opción constituye un objetivo todavía pendiente.

46 En teoría, también es válido presentar otra documentación de carácter oficial para demostrar dicha permanencia. No obstante, en la práctica, Extranjería suele denegar las solicitudes por no considerar suficientemente probada la continuidad exigida.

47 José Zarauz, Incidencia del padrón municipal en el ejercicio de los derechos de las personas extranjeras en situación irregular (Colección de Derechos Humanos Padre Francisco de Vitoria, 2007) 233.

${ }^{48}$ Entrevista propia a Norma, activista de Sindihogar y asesora en extranjería

(10 de septiembre de, 2020).

49 'Barcelona facilitará el empadronamiento sin domicilio fijo a vecinos que carezcan

de un hogar estable' (La Vanguardia, 2016)

$<$ https://www.lavanguardia.com/local/barcelona/20161219/412732511652/barcelo na-empadronamiento-sin-domicilio-

fijo.html\# : : text=El\%20Ayuntamiento\%20de $\% 20$ Barcelona $\% 20$ ha, otras $\% 20$ circu 
La segunda cuestión que interesa destacar en cuanto los requisitos para el arraigo social es la exigencia de un contrato de trabajo a jornada completa (o varios contratos cuya suma alcance una jornada semanal de 30 horas) durante un periodo mínimo de un año. En general, las mujeres que trabajan en la economía sumergida no tienen muchas más opciones que el trabajo de limpieza o cuidados en casas particulares. $Y$, en este sentido, es fundamental considerar el hecho de que el trabajo del hogar ha sido realizado históricamente sin formalizar el contrato correspondiente. 50

Quizás lo siguiente ayude a ejemplificar las dificultades que para las trabajadoras del sector presenta la exigencia de un contrato. A raíz de las problemáticas que la pandemia contribuyó a visibilizar, en el año 2020 la Generalitat de Catalunya aprobó el Decret Llei 25/2020, de 16 de juny, de mesures extraordinàries en matèria social i de caràcter fiscal i administratiu. El decreto creó una línea de subvenciones dirigida a personas empleadoras para solventar los costos de la Seguridad Social (SS) correspondientes a trabajadoras contratadas para el cuidado de personas en situación de dependencia. La finalidad era fomentar la contratación en este ámbito -especialmente de trabajadoras que se encontraban en situación irregular y que en ese momento cumplían los requisitos para el arraigo social-, a la vez que se contribuía a paliar las necesidades generadas por la dependencia.

Desde Sindihogar se contactó a 79 trabajadoras. Dos tercios de estas mujeres no habían cumplido los tres años en el país, o bien no podían demostrarlo mediante el padrón. De las 26 que sí satisfacían ese requisito, 15 trabajaban pocas horas en muchos domicilios, y la convocatoria exigía un mínimo de 10 horas semanales por contrato.

Apenas 11 mujeres cumplían con las condiciones requeridas para ser contratadas y para acceder luego al arraigo social. En muchos de estos casos se medió con la parte empleadora, ${ }^{51}$ acudiendo en la argumentación a los beneficios que conlleva formalizar un contrato para ambas partes de la relación laboral; sobre todo teniendo en cuenta la oportunidad que ofrecía la convocatoria en cuanto gastos de SS. Sin embargo, no se logró materializar ningún contrato de trabajo. La causa principal fue que la remuneración de las trabajadoras estaba muy por debajo del salario mínimo interprofesional. Entonces, si bien las familias empleadoras se ahorraban más de 200 euros por mes en cotizaciones, si querían acceder a la subvención debían aumentar el salario de la cuidadora ( $y$ en muchos casos ese aumento significaba abonar al menos el doble de lo que se venía pagando). ${ }^{52}$

nstancias\%20de\%20vulnerabilidad\%20habitacional> última consulta el 23 de noviembre de 2021.

${ }^{50}$ Ruth Mestre i Mestre, 'Por qué las inmigrantes no trabajan. Breve crítica feminista al derecho de extranjería' (1999) 36, Jueces para la democracia, 22.

51 En otros, las trabajadoras han preferido negociar ellas mismas con sus empleadores o empleadoras; decisión que ha sido respetada por parte de Sindihogar. 52 De estas 11 mujeres (que trabajaban 40 horas semanales 0 más), las remuneraciones eran las siguientes: techo y comida, en un caso; 500, 570, 700, 800, 
A nivel general, la convocatoria no fue precisamente un éxito: de la totalidad de plazas ofrecidas, se terminaron por cubrir menos de la mitad.

Esta situación dejó al descubierto la cantidad de problemas que envuelven al sector. Se ha evidenciado la desprotección social que afecta a las trabajadoras y la subestimación de las labores que realizan; así como el hecho de que estas mujeres están pagando las deudas de un Estado prácticamente ausente en materia de dependencia. Pero en lo que atañe a este punto de la investigación, interesa destacar especialmente la atroz falta de interés por parte de la clase política en cuanto a las dificultades que significa para las trabajadoras del sector obtener un contrato de trabajo de un año y a jornada completa, considerando que éste constituye un requisito indispensable para residir y trabajar legalmente en el país.

Fomentar la contratación de las trabajadoras no parece, entonces, la medida óptima dirigida a atacar el problema de la irregularidad -aunque de hecho sí lo sea para otros problemas que presenta el sector-. Según lo analizado, es probable que parte de la solución esté en eliminar la exigencia de un contrato de trabajo para poder acceder a derechos fundamentales; en abandonar la absurda idea de que el reconocimiento de las personas migrantes como sujeto de derechos se debe supeditar a la formalización de unas relaciones laborales determinadas. ${ }^{53} \mathrm{Al}$ respecto, se ha afirmado que «se pueden propiciar cambios en la Ley de extranjería que faciliten la obtención de los papeles necesarios a partir del arraigo y no a partir del contrato laboral». ${ }^{54}$ No obstante, una modificación de la normativa en este sentido no sería suficiente, pues no se estaría atacando la exigencia de permanecer en territorio español durante tres años de manera irregular. Lo cual, como ya se ha señalado, vulnera notoriamente los derechos de las personas migrantes.

Ahora bien, aunque estas mujeres consigan, por fin, un contrato de trabajo ( $y$ con ello accedan al arraigo social), la situación de precariedad no cambia demasiado. Porque la autorización por circunstancias excepcionales tiene una vigencia de apenas un año, y pasado dicho plazo se debe solicitar la autorización de residencia y trabajo, la cual es concedida si se cumple con ciertos requisitos. ${ }^{55}$ Concretamente, se exige demostrar la continuidad de la relación

850 o 900 euros mensuales en los demás. Mientras que el salario mínimo interprofesional está fijado en 12 pagas de 1108,3 euros.

53 Celeste Arella y otros, Una aproximación a la vulneración de los derechos humanos de las trabajadoras sexuales en la ciudad de Barcelona (Universidad de Barcelona, Observatori del Sistema Penal i els Drets Humans 2006); Emmanuel Rodríguez, El gobierno imposible. Trabajo y fronteras en las metrópolis de la abundancia (Traficantes de Sueños, 2003).

54 Dolores Juliano, 'Género y trayectorias migratorias en época de crisis' (2012) 97/3 Papers 536.

55 Real Decreto 557/2011, de 20 de abril, por el que se aprueba el Reglamento de la Ley Orgánica 4/2000, sobre derechos y libertades de los extranjeros en España y su integración social, artículo 202. 
laboral que dio origen a la primera autorización. También puede obtenerse si se ha trabajado al menos 6 meses, siempre y cuando se cuente con un nuevo contrato de trabajo, o 3 meses, si además se demuestra que el primer contrato se interrumpió por causas ajenas a la voluntad de la trabajadora y que ésta ha buscado activamente empleo desde entonces. ${ }^{56} \mathrm{Sin}$ embargo, en la práctica, finalizar la relación laboral antes del año de trabajo significa correr el riesgo de que la solicitud de residencia y trabajo sea denegada. ${ }^{57}$

Trabajas muchísimo. No vas más días a la semana porque no hay [...]. Cuando una está en el proceso de hacer los papeles, se hace de todo para cumplir con las obligaciones y quedar bien. Lo único que te interesa es eso. 58

Al Estado le sale a cuenta: es sabido que, al menos durante ese periodo de tiempo, habrá personas dispuestas a realizar los peores trabajos en condiciones sospechosas a cambio de un salario inferior al correspondiente. En definitiva, la sociedad española termina por beneficiarse a costa de miles de personas que sin chistar hacen lo necesario para poder sobrevivir durante tres años en clandestinidad, y luego para mantener una situación de regularidad siempre amenazada por la pérdida del contrato que la posibilitó.

De esta manera, la brecha entre las personas incluidas y las marginadas o excluidas se hace cada vez más amplia. La ciudadanía termina por conformar un verdadero privilegio de status ${ }^{59} \mathrm{y}$, correlativamente, la normativa sobre extranjería acaba por generar y sostener un nuevo apartheid social. ${ }^{60}$

\section{3.- LA INCOMPLETUD DE LA REGULACIÓN DEL TRABAJO DEL HOGAR}

A decir verdad, el servicio de limpieza y de cuidados en domicilios particulares continúa sin ser reconocido como un verdadero trabajo. De ello da cuenta la realidad ya señalada sobre la alta tasa de informalidad que caracteriza al sector, así como el hecho de que la normativa respectiva es a todas luces precaria y está marcadamente diferenciada de otros ámbitos laborales.

Históricamente, estas desigualdades han sido justificadas en base al peculiar carácter del lugar donde se presta el servicio. Es decir, como estas labores se realizan en un entorno íntimo, se ha entendido que es apropiado regular la actividad con cierta distancia en relación a la normativa general. Pero el problema no es la diferencia en sí misma,

\footnotetext{
56 Ibid artículo 71.

57 Entrevista propia a Norma, activista de Sindihogar y asesora en extranjería (20 de julio de 2021).

58 Entrevista propia a Gabi, activista de Sindihogar (14 de agosto de 2020).

59 Luigi Ferrajoli, Derechos y garantías. La ley del más débil (Trotta, 2004$) 32$.

60 Emmanuel Rodríguez, El gobierno imposible. Trabajo y fronteras en las metrópolis de la abundancia (Traficantes de Sueños, 2003) 122.
} 
sino el hecho de que bajo el eufemismo «especial» se esconden verdaderas desigualdades sociolaborales.

En razón de las deficiencias históricas (y globales) del sector, en el año 2011 la Organización Internacional del Trabajo (OIT) adoptó el Convenio 189 sobre las Trabajadoras y los Trabajadores Domésticos. ${ }^{61}$ El documento estipula unas condiciones mínimas a respetar por parte de los Estados que lo ratifican. En general, las disposiciones tienden a equiparar los derechos de las trabajadoras del hogar con los reconocidos a personas empleadas en otros sectores.

Entre los puntos más importantes, el convenio establece el deber de adoptar medidas para la protección efectiva contra toda forma de abuso, acoso y violencia; ${ }^{62}$ asegurar unas condiciones de empleo equitativas y condiciones de trabajo decente; ${ }^{63}$ garantizar la igualdad de trato entre las trabajadoras del sector y los trabajadores en general en relación a las horas normales de trabajo, la compensación de las horas extraordinarias, los períodos de descanso, las vacaciones anuales y en lo relativo a la protección de la seguridad social; 64 garantizar la seguridad y la salud en el trabajo; ${ }^{65}$ adoptar medidas relativas a la inspección del trabajo y la aplicación de las normas y las sanciones; 66 considerar las horas de presencia como horas de trabajo; ${ }^{67}$ detallar las condiciones de los pagos en especie y que el valor monetario que se atribuya a los mismos sea justo y razonable. ${ }^{68}$

España no ratificó el convenio, pero sí introdujo ciertas modificaciones en la regulación del sector. En el mismo año en que fue adoptado el documento de la OIT, mediante la Ley 27/2011, de 1 de agosto, se procedió a integrar el Régimen Especial de Empleados del Hogar ${ }^{69}$ en el Régimen General de la Seguridad Social (RGSS). Y apenas unos meses después se aprobó el Real Decreto 1620/2011, de 14 de noviembre, por el que se regula la relación laboral especial del servicio del hogar familiar.

${ }^{61}$ De manera complementaria, la OIT adoptó la Recomendación 201, homónima, de carácter no vinculante, que establece medidas más concretas y exigentes en esta materia, y que sirve como guía a los Estados que ratifiquen el convenio para implementar las políticas pertinentes.

62 Convenio 189 sobre las Trabajadoras y los Trabajadores Domésticos, artículo 5.

63 Ibid artículo 6.

${ }^{64}$ Ibid artículo 10 y 14.

65 Ibid artículo 13.

66 Ibid artículo 17.

67 Ibid artículo 11.

68 Ibid artículo 12.

69 Históricamente existió un ámbito de protección específico para las empleadas del hogar, diferenciado del régimen de los demás sectores laborales. Entre otras cuestiones, no se reconocía la existencia de accidentes de trabajo, la baja por enfermedad se cobraba a partir del día 29 y el alta en la Seguridad Social no era obligatoria en todos los casos. 


\section{1.- La normativa sobre seguridad social}

En relación a la primera modificación, es importante destacar que la inclusión del Régimen Especial en el RGSS no fue total, ya que el sector quedó integrado en un sistema especial:

Con efectos de 1 de enero de 2012, el Régimen Especial de la Seguridad Social de los Empleados de Hogar quedará integrado en el Régimen General de la Seguridad Social, mediante el establecimiento de un sistema especial para dichos trabajadores [....$^{70}$

El sistema que regula actualmente el sector sigue conservando importantes divergencias en relación al régimen común: no tienen derecho a la protección por desempleo; las cotizaciones deben determinarse de acuerdo a una escala prefijada configurada en función de las remuneraciones percibidas, lo cual significa que las trabajadoras no pueden cotizar según sus salarios reales; y para el cálculo de la base reguladora de las pensiones solo se tienen en cuenta los periodos realmente cotizados, es decir, no se integran las llamadas «lagunas de cotización».

Según la Ley 27/2011, las reformas necesarias para una verdadera equiparación del sistema de cotizaciones iban a ser implementadas gradualmente hasta el año 2018, de manera que a partir del año 2019 las trabajadoras comenzaran a cotizar por salarios reales. En relación al paro, el Real Decreto 1620/2011, en su DA 2.2, ordenaba la constitución de un grupo de expertos nombrados por el propio Ministerio de Trabajo, cuyo objetivo sería evaluar, entre otras cuestiones, la posibilidad de implementar un sistema de protección por desempleo.

En lo que respecta a las cotizaciones, el Partido Popular, mediante la Enmienda 6777 a la Ley de Presupuestos del Estado para el año 2018, propuso al Parlamento español atrasar cinco años más las modificaciones legales que las trabajadoras estaban esperando. La enmienda fue finalmente aprobada. Actualmente, el último pacto PSOE-Podemos ha dejado su implantación para enero de 2023. En relación a la protección por desempleo, baste mencionar que el grupo de expertos nunca existió.

Como se desprende de ello, la protección social de las afiliadas continúa regulada por aquel sistema especial. Al día de hoy, la base más baja de cotización es de 206 euros, y sin embargo es alta en relación a los salarios que pagan quienes contratan unas pocas horas semanales. Como consecuencia de ello, la mayor parte de esos contratos se mantienen en la economía sumergida. De igual manera, la falta de cobertura de vacíos en el cálculo de las pensiones tiene consecuencias obvias en el futuro de las trabajadoras. Por último, huelga decir que, en un contexto de crisis económica y sanitaria, no tener reconocido el derecho al paro resulta inadmisible.

\footnotetext{
70 Ley $27 / 2011$, de 1 de agosto, sobre actualización, adecuación y modernización del sistema de Seguridad Social, Disposición adicional 39.1.
} 
En el año 2012 se aprobó otra reforma al régimen. Se trata del Real Decreto-ley 29/2012, de 28 de diciembre, de mejora de gestión y protección social en el Sistema Especial para Empleados de Hogar y otras medidas de carácter económico y social. Teniendo en cuenta las medidas adoptadas por esta normativa, su denominación resulta, cuanto menos, irónica.

El RDL estipula que aquellas trabajadoras que presten sus servicios durante menos de 60 horas mensuales por persona empleadora pueden acordar con ésta asumir la responsabilidad de registrar su afiliación, altas, bajas y variaciones de datos en la Seguridad Social. Al respecto, Isabel Otxoa, profesora de derecho del trabajo en la Universidad del País Vasco y activista en la Asociación de Trabajadoras del Hogar de Bizkaia (ATH), ha señalado que:

La medida tiene un efecto muy amplio. El contrato a tiempo parcial por debajo de las 15 horas semanales es frecuente en el empleo de hogar [...]. La vuelta a la cotización a cargo de la trabajadora la coloca ahora en una situación más difícil que la que tenía en el desaparecido Régimen Especial, en un aspecto importante. Antes, quien denunciaba a su empleador ante la Seguridad Social quizá no pudiese demostrar las horas de trabajo que la hacían acreedora del derecho al alta (20 a la semana), pero al menos no tenía miedo a que la denuncia se volviese en su contra, resultando obligada a pagar ella todas las cuotas desde la primera hora. ${ }^{71}$

En pocas palabras, la regulación española actual en materia de seguridad social está en evidente conflicto con lo establecido en el Convenio 189 de la OIT. En este sentido, resulta absolutamente inaceptable que existan sectores laborales discriminados en aspectos tan fundamentales, específicamente en lo que respecta al acceso a la prestación por desempleo.

\section{2.- La normativa laboral}

Una cuestión íntimamente vinculada con la normativa sobre (infra)protección social es la regulación de las relaciones laborales del sector comprendida en el Real Decreto 1620/2011, en cuyo artículo 1.4 establece:

El objeto de esta relación laboral especial son los servicios o actividades prestados para el hogar familiar, pudiendo revestir cualquiera de las modalidades de las tareas domésticas, así como la dirección o cuidado del hogar en su conjunto o de algunas de sus partes, el cuidado o atención de los miembros de la familia o de las personas que forman parte del ámbito doméstico o familiar, y otros trabajos que se desarrollen formando parte del conjunto de tareas domésticas, tales como los de guardería, jardinería, conducción de vehículos y otros análogos. 71 Isabel Otxoa, 'La nueva regulación de las trabajadoras del hogar' (2012) 12,
Themis Revista jurídica de igualdad de género, 34 . 
Interesa destacar la amplitud de esta definición. Prácticamente cualquier tarea que se realice en el ámbito del hogar se considera objeto de la relación laboral. Limpiar, cocinar, acompañar a los niños a la escuela o atender a una persona en situación de dependencia son actividades que se convierten en responsabilidad lógica de la trabajadora. Así, una mujer contratada para limpiar un hogar de pronto puede ver acrecentado su trabajo si un miembro de la familia se incapacita; o una cuidadora interna puede verse obligada a trabajar durante la supuesta pernocta si aumenta el grado de dependencia de la persona atendida. Esta falta de concreción en las actividades da pie a abusos por parte de las familias empleadoras, aunque éstas no siempre sean conscientes de ello.

Es cierto que el RD 1620/2011 significó una mejora en el régimen laboral del sector, pues la normativa vigente hasta esa fecha ${ }^{72}$ era notoriamente perjudicial para las trabajadoras; entre otras cosas, permitía descontar hasta el $45 \%$ del salario en concepto de manutención, no establecía la obligación de pagar las horas de presencia y el descanso entre jornadas estaba fijado en 10 horas para las externas y 8 horas para las internas. Sin embargo, la regulación legal del sector todavía contiene aspectos injustos, y los derechos ya reconocidos tienen unas garantías muy débiles.

En cuanto la remuneración, cabe señalar que el pago en especie constituye una cuestión indeterminada y que ello repercute en el salario de la trabajadora. El artículo 8.2 del RD se limita a expresar que se puede descontar, en concepto de alojamiento y manutención, el porcentaje que las partes acuerden, siempre y cuando quede garantizado el pago en metálico de la cuantía del salario mínimo interprofesional y sin que pueda resultar un porcentaje de descuento superior al $30 \%$ del salario total. Al no detallarse la cuantía correspondiente a cada consumo, nadie sabe cuánto cuesta la comida y las noches de alojamiento, y da igual si la trabajadora come y duerme dos, tres, o seis veces a la semana. Lógicamente, toda esta indeterminación acaba por afectar la remuneración percibida. ${ }^{73}$ Asimismo, parece importante señalar que, en la práctica, ni siquiera se respeta lo establecido por el $\mathrm{RD}$, ya que buena parte de las trabajadoras no alcanza a cobrar en metálico el salario mínimo correspondiente. ${ }^{74}$

Uno de los aspectos más discriminadores de la normativa laboral es la figura del despido por desistimiento del empleador. Se trata de

\footnotetext{
72 Real Decreto 1424/1985, de 1 de agosto, por el que se regula la relación laboral de carácter especial del Servicio del Hogar Familiar.

73 Isabel Otxoa, 'La nueva regulación de las trabajadoras del hogar' (2012) 12, Themis Revista jurídica de igualdad de género, 34.

${ }^{74}$ En el año 2020, por ejemplo, según las estadísticas de las asesorías realizadas en ATH-ELE de Bizkaia, «Sobre el conjunto de todas las internas de entresemana, el $96,73 \%$ no cobraba en metálico el salario mínimo que le correspondía por sus horas de trabajo». Ver 'Estadísticas' (ATH-ELE, 2020) <https://athele.com/es/estadisticas/> última consulta el 23 de noviembre de 2021.
} 
una manera de extinguir el contrato sin necesidad de alegar causa alguna; con un periodo de preaviso de veinte o siete días según se haya superado o no el año de prestación de servicios; y con una indemnización equivalente al salario correspondiente a doce días naturales por año de trabajo, con el límite de seis mensualidades. En definitiva, el despido por desistimiento constituye una forma de dar por concluida la relación laboral bajo condiciones menos exigentes para la parte empleadora que un despido por causas objetivas. ${ }^{75}$

En materia de prevención de riesgos laborales, el RD establece que la parte empleadora está obligada a adoptar medidas eficaces para que el trabajo en el hogar se realice en las debidas condiciones de seguridad y salud. ${ }^{76}$ Sin embargo, no existe mayor regulación al respecto; pues, coherentemente con ello, la Ley 31/1995, de 8 de noviembre, de prevención de Riesgos Laborales determina que:

La presente Ley tampoco será de aplicación a la relación laboral de carácter especial del servicio del hogar familiar. No obstante lo anterior, el titular del hogar familiar está obligado a cuidar de que el trabajo de sus empleados se realice en las debidas condiciones de seguridad e higiene. ${ }^{77}$

La normativa general sobre riesgos laborales destina esta única disposición a la regulación del sector, y lo hace para excluirlo y enunciar una tibia e indeterminada obligación adjudicada a la parte empleadora. No se establecen las condiciones de esa exigencia ni las sanciones correspondientes por incumplirlas, así como tampoco las maneras de garantizar los derechos de las trabajadoras en ese ámbito. No existen formaciones en materia de prevención de riesgos laborales para quien emplea ni para quien trabaja. En definitiva, no hay herramientas, ni recursos, ni controles. Esta laguna en la legislación tiene efectos evidentemente perjudiciales para las trabajadoras, sobre todo considerando el contexto pandémico actual.

Seguimos con el viejo concepto de que el trabajo doméstico y de cuidado en el hogar no necesita [y] no contiene saberes, y que podemos desempeñarlo en base a cualidades femeninas innatas. Muchas veces, las frecuentes lesiones músculo-esqueléticas y la fatiga mental no son reconocidas como accidentes laborales. ${ }^{78}$

Por último, cabe señalar que, sin perjuicio de lo analizado hasta el momento, existen muchos derechos ya reconocidos que no se

75 En el despido por causas objetivas la indemnización es de veinte días por año de servicio y con un máximo de doce mensualidades (Real Decreto Legislativo 2/2015, de 23 de octubre, por el que se aprueba el texto refundido de la Ley del Estatuto de los Trabajadores, art. 53.1).

76 Real Decreto 1424/1985, de 1 de agosto, por el que se regula la relación laboral de carácter especial del Servicio del Hogar Familiar, artículo 7.2.

77 Ley 31/1995, de 8 de noviembre, de prevención de Riesgos Laborales, artículo 3.4. 78 Isabel Otxoa, 'Con y sin Convenio 189, todos los derechos para las trabajadoras del hogar' (Viento Sur, 27 de junio de 2018) $<$ https://www.eldiario.es/opinion/tribuna-abierta/convenio-oit-derechostrabajadoras-hogar 129 2048596.html> última consulta el 23 de noviembre de 2021. 
respetan debido a la carencia de mecanismos para garantizar el cumplimiento de las condiciones generales en las que se lleva a cabo la actividad:

El RD 1620/2011 [...] establece el contrato escrito con detalle de todas las condiciones de trabajo, derecho a cobrar todas las horas a disposición del empleador, jornada máxima de 40 horas de trabajo y 20 de presencia, descanso de 12 horas entre jornadas, derecho a la integridad física, respeto a la intimidad... no seguiré. La realidad es que, según las estadísticas de la $A T H-E L E$, un tercio de la gente no tiene contrato, cuando lo tiene no refleja las verdaderas condiciones pactadas o impuestas, en el trabajo interno un $72 \%$ tiene una jornada habitual superior a las 60 horas semanales, y solo un $30 \%$ tiene el descanso semanal establecido de 36 horas continuadas. ${ }^{79}$

Es sabido que, como la actividad tiene lugar en el entorno familiar y el «domicilio es inviolable», ${ }^{80}$ los inspectores no pueden efectuar controles como de hecho lo hacen en cualquier otro espacio de trabajo. Al respecto, el artículo 13.1 de la Ley 23/2015 establece lo siguiente:

[Los inspectores pueden] Entrar libremente en cualquier momento y sin previo aviso en todo centro de trabajo, establecimiento o lugar sujeto a inspección y a permanecer en el mismo. Si el centro sometido a inspección coincidiese con el domicilio de una persona física, deberán obtener su expreso consentimiento o, en su defecto, la oportuna autorización judicial (cursivas agregadas).

No obstante, si bien es cierto que la inexistencia de inspecciones de trabajo en los hogares posiciona a las trabajadoras en un lugar de infraprotección, no debemos olvidar que el desinterés estatal se evidencia en faltas cotidianas mucho más simples. Baste mencionar la carencia de controles básicos, como los relativos a la actualización de las cotizaciones en el empleo de hogar, obligación que corresponde a la Tesorería General de la Seguridad Social. ${ }^{81}$ Ello se considera una clara muestra de la falta de voluntad política real para mejorar, de manera efectiva, las condiciones del sector.

\section{4.- LUCHAR DESDE LOS CUIDADOS: EL CASO DE SINDIHOGAR}

En Barcelona, hace casi una década, distintas asociaciones de mujeres del sector llegaron a la conclusión de que la estructura sindical era conveniente para la organización colectiva. Esta opción era la única manera de hacerse con las herramientas necesarias para poder interpelar a las autoridades, a la vez que ello permitía conservar la independencia con respecto a otros sindicatos:

En el 2010 tocamos todas las puertas, y siempre nos terminaban mandando a los sindicatos mayoritarios. Entendimos que como

\footnotetext{
${ }^{79}$ Ibid.

${ }^{80}$ Constitución Española, artículo 18.

${ }^{81} \mathrm{Al}$ respecto ver Isabel Otxoa, 'Sigue el fraude de la Seguridad Social' (Viento Sur, 22 de febrero de 2020) <https://vientosur.info/sigue-el-fraude-de-la-seguridadsocial/> última consulta el 23 de noviembre de 2021.
} 
mujeres no podíamos seguir siendo asociación [...]. Fue una decisión que nos costó mucho, pero decidimos ser un sindicato, porque con esa estructura tenemos derecho a la interlocución con el Estado, cosa que no pasa con las asociaciones y las ONG. ${ }^{82}$

El derecho a sindicarse está reconocido en la Constitución Española y actualmente se encuentra regulado por la Ley Orgánica 11/1985, de 2 de agosto, de Libertad Sindical. Según el artículo 7 de la $C E$, la finalidad de este tipo de entidad es contribuir a la defensa y promoción de los intereses económicos y sociales que les son propios.

Ahora bien, parece importante señalar que el empleo de hogar presenta dificultades en relación al ejercicio de los derechos colectivos del trabajo, sobre todo en lo relativo a la negociación colectiva. Pues, entre otros problemas que envuelven al sector (derivados de la especialidad adjudicada al mismo), la falta de una organización patronal obstaculiza la constitución de un convenio colectivo, al menos bajo la legislación vigente en la materia. Por esta razón, hay quien sostiene la importancia de adaptar la normativa general sobre derechos colectivos a la relación especial del servicio del hogar familiar. ${ }^{83}$

En este contexto, la organización de las trabajadoras es fundamental. Pues, a pesar de los obstáculos que se presentan para ejercitar los derechos colectivos en igualdad de condiciones con otros sectores, la agrupación común y organizada de quienes se encuentran trabajando en este sistema precario es precisamente la vía para alcanzar derechos, tanto individuales como colectivos.

[Sindihogar] se estructura por la transformación de múltiples experiencias asociacionistas, de las cuales las trabajadoras eran parte, que derivan en la construcción de una organización de base sindical. La misma tiene como objetivo reivindicar sus derechos como trabajadoras y denunciar las condiciones de trabajo dentro de la precariedad económica (economía sumergida, bajos salarios, falta de cobertura por desempleo), política (escaso nivel de organización, dificultades para la negociación ante sus empleadores y otros actores sociales) y social (desvalorización e infravaloración de su trabajo, discriminación por raza/etnia, género, sexualidad). ${ }^{84}$

En este sentido, si bien muchas de las demandas del sindicato giran en torno a las condiciones laborales de las trabajadoras, otras se dirigen hacia objetivos que trascienden ese ámbito y que tienen que ver con las discriminaciones que resultan de una política migratoria restrictiva y de un discurso social racista y machista. Es decir, estas

\footnotetext{
82 Entrevista propia a Norma, activista de Sindihogar y asesora en extranjería (10 de septiembre de 2020).

83 Concepción Sanz Sáez, 'Los derechos colectivos del trabajo doméstico con relación al Estatuto de los Trabajadores' (2021) 45, Lan Harremanak, 138.

84 Karina Fulladosa Leal, 'Mujeres en movimiento: ampliando los márgenes de participación social y política en la acción colectiva como trabajadoras del hogar y el cuidado' (Tesis Doctorals en Xarxa, 2020) $<$ https://www.tesisenred.net/handle/10803/455567\#page=183 > última consulta el 23 de noviembre de 2021.
} 
reivindicaciones exceden las que han sido tradicionalmente planteadas por los sindicatos, ya que además incluyen cambios generales relativos a la calidad de vida. 85

El principio rector que ha guiado el accionar de Sindihogar durante todos estos años se corresponde con la idea de poner los cuidados en el centro. Y cabe aclarar que esta expresión no es solo un eslogan bonito, y que tampoco está del todo vinculada con la actividad remunerada que realizan muchas trabajadoras. Se trata, más bien, de una manera de hacer política desde otro lugar. En este sentido, es posible afirmar que Sindihogar ha re-significado la idea tradicional de organización sindical, no solo a partir de la reivindicación de un sector cuyas demandas han sido históricamente desdeñadas; sino también a partir de una forma propia de organizarse, trabajar y manifestarse. ${ }^{86}$

Sindihogar posee una estructura horizontal, 87 democrática y autogestionaria. La independencia económica respecto de otras entidades constituye un eje central en la organización del colectivo. Por esta razón, las activistas gestionan el espacio a partir de proyectos pensados y concretados en el seno del sindicato: talleres artísticos, servicios de catering, ventas de bolsos y camisetas con consignas reivindicativas, entre otras.

La organización colectiva de las activistas en el marco de las problemáticas derivadas del COVID-19 proporciona un buen ejemplo de las prácticas cotidianas de Sindihogar. Desde los comienzos de la pandemia, muchas de las afiliadas han visto gravemente afectados sus ingresos, ya sea por despidos arbitrarios, ya sea porque, a causa de las restricciones, no han podido seguir ejerciendo las actividades que normalmente realizaban. La etapa más dificultosa fue la comprendida

85 Tal como explica Galcerán Huguet: «En cuanto a las reivindicaciones, en las luchas de las mujeres hay algunas que se solapan con las de sus compañeros varones, como por ejemplo la reducción de horarios. [...] pero otras son específicas, tales como [...] la obligación de que las empresas tengan guarderías para los niños, el que se instalen comedores colectivos y salas de reunión, etc. Eso implica que los movimientos de mujeres, incluso en sus incipientes formas tienen muy presente no sólo las exigencias estrictamente sindicales como la reducción de horarios o la subida de salarios, sino que incluyen cambios en las condiciones de vida». Ver Montserrat Galcerán Huguet 'Introducción: Producción y reproducción en Marx' en Laboratorio Feminista (ed) Transformaciones del trabajo desde una perspectiva feminista. Producción, reproducción, deseo, consumo (Tierradenadie, 2006) 16.

86 Estas prácticas tienen que ver con lo cotidiano (por ejemplo, ofrecer un espacio para la infancia), con las redes que se tejen con otros colectivos de mujeres (siempre de manera horizontal, sin caer en parternalismos o posiciones victimistas) y con los espacios de autonomía que han generado (a nivel organizativo y de gestión). Al respecto ver Karina Fulladosa Leal, 'Mujeres en movimiento: ampliando los márgenes de participación social y política en la acción colectiva como trabajadoras del hogar y el cuidado' (Tesis Doctorals en Xarxa, 2020) $<$ https://www.tesisenred.net/handle/10803/455567\#page $=183>$ última consulta el 23 de noviembre de 2021.

87 Cabe aclarar que el artículo 4.2 de la LO 11/1985 de Libertad Sindical requiere la elección de órganos de representación, gobierno y administración, lo cual implicaría una jerarquía entre las integrantes del grupo. Sin embargo, en Sindihogar estos cargos existen a efectos meramente formales. 
entre marzo y agosto del 2020, es decir, los meses de estricto confinamiento y los inmediatamente posteriores. Al respecto, la única medida establecida por el gobierno consistió en un subsidio extraordinario único cuya implementación fue, cuanto menos, ineficiente. En noviembre de 2020, esto es, ocho meses después de decretado el estado de alarma, dicho subsidio había sido percibido por menos de la mitad de las solicitantes. ${ }^{88}$ Además, el mismo estaba previsto para las trabajadoras afiliadas a la SS, por lo cual miles de mujeres quedaron excluidas de la mencionada medida.

En este contexto, Sindihogar organizó una caja de resistencia apelando a la reciprocidad: se realizó un taller textil, dictado por una de las activistas, con la finalidad de que el grupo aprenda a hacer muñecas de tela que serían entregadas a quienes aportasen a la caja del sindicato. Gracias a este proyecto, las compañeras pudieron pagar sus alquileres durante más de cuatro meses, a la vez que se erigieron en agentes de cambio de su propia realidad, en el sentido de estar participando de manera activa en la lucha por un objetivo común y concreto.

De alguna manera, el sindicato asume las responsabilidades que las instituciones desestiman. Debido a que los derechos reconocidos (a nivel tanto internacional, como estatal y autonómico) se quedan a medio camino por falta de mecanismos tendentes a garantizar su cumplimiento, las activistas asumen esos deberes de manera recíproca, con la finalidad de que todas puedan, al menos en parte, dotar de contenido a los derechos tan alegremente proclamados en el marco institucional. 89

\section{5.- PROPUESTAS REgULADORAS PARA CUIDAR A LAS QUE CUIDAN}

A propósito de las reflexiones y las discusiones que se sostuvieron durante el Encuentro Estatal del Grupo de Acción Política de Trabajadoras del Hogar y de los Cuidados, ${ }^{90}$ celebrado en octubre del 2020 en Barcelona, se generaron distintas propuestas que atañen

\footnotetext{
88 'Pagad ya el subsidio extraordinario para las trabajadoras de hogar; incluid en los presupuestos de 2021 la prestación por desempleo' (Grupo de Acción Política, 06 de noviembre de 2020) <https://sindillar.org/comunicado-30-de-marzo-diainternacional-de-las-trabajadoras-de-hogar/> última consulta el 23 de noviembre de 2021.

${ }^{89}$ En este sentido, se ha señalado que «El concepto de derecho se construye a partir de la noción de deber, y no a la inversa. Alguien tiene un derecho si y sólo si los demás -incluidas las instituciones - tienen deberes a su respecto (esto es, deberes acerca de aquello que se trata de proteger con cualquier noción determinada de derecho)». Ver Juan Ramón Capella, 'Derechos, deberes: La cuestión del método de análisis' en José A. Estévez Araújo (ed) El libro de los deberes. Las debilidades e insuficiencias de la estrategia de los derechos (Trotta, 2013) 46.

90 Sindihogar fue la entidad encargada de la organización, dentro del marco del Grupo de Acción Política, integrado por distintas asociaciones del sector pertenecientes a seis comunidades autónomas.
} 
al sector, algunas bastante concretas y otras todavía embrionarias, las cuales se resumen a continuación.

La normativa sobre extranjería estuvo muy presente en las discusiones que tuvieron lugar en el encuentro. Se trata de una problemática que no siempre ha sido considerada entre las reivindicaciones de las trabajadoras, habida cuenta de que hasta finales del milenio pasado los flujos migratorios poseían una magnitud bastante inferior a la actual, y por extensión las mujeres migrantes estaban lejos de integrar la mayor parte del sector. ${ }^{91}$

Ahora bien, si se considera la composición actual del sector, es posible afirmar que, aunque se reconozcan los derechos exigidos y se tomen todas las medidas pertinentes para asegurar un efectivo ejercicio de los mismos, dicho reconocimiento estaría sesgado porque las destinatarias serían (exclusivamente) las mujeres que trabajan de manera formal. $Y$, como al menos un tercio de las trabajadoras ejerce la actividad en la economía sumergida, una gran parte del colectivo tendría vedado el ejercicio de esos derechos. ${ }^{92}$

En ese marco, entonces, se planteó la necesidad de situar esta problemática en el centro de las discusiones relativas a los derechos de las trabajadoras del sector. Como medida paliativa, se subrayó la importancia de presionar al gobierno español con la finalidad de que se convoque una regularización de todas las personas migrantes que actualmente se encuentran en situación administrativa irregular. La urgencia de esta demanda se fundamenta en la precariedad en la que se halla una gran parte de la sociedad, agravada por las consecuencias sociales y económicas de la pandemia. En este sentido, se señaló que la única forma de obtener algún logro en este aspecto es salir a las calles, hacer ruido, convertirse en una molestia.

Como medida curativa se insistió en la adopción de una política migratoria que no vulnere los derechos de las personas migrantes, específicamente en lo relativo a la residencia y al trabajo formal. Puede que este objetivo parezca poco realista en el corto plazo, pero como ha señalado Ferrajoli, menos realista es pensar que las fronteras cerradas pueden convivir con un futuro de paz. ${ }^{93}$

\footnotetext{
91 Al respecto, se ha señalado que en el año 1996 las personas extranjeras representaban apenas un $7 \%$ del total de empleadas de hogar. Ver Sandra Ezquerra, 'Crisis de los cuidados y crisis sistémica: la reproducción como pilar de la economía llamada real' (2011) 2 Investigaciones Feministas 175, 188.

92 Al respecto, se pueden consultar los datos proporcionados por la Encuesta de Población Activa y los relativos a las afiliaciones de la Seguridad Social. En este sentido, se ha señalado que «La puesta en común de ambos datos muestra que en España solo el $68 \%$ de las personas que dicen que trabajan como empleadas del hogar están dadas de alta a la Seguridad Social, es decir, que una de cada tres trabaja en la "economía sumergida"». Ver 'Una de cada tres empleadas del hogar quedará fuera de la ayuda extraordinaria' (La Vanguardia, 29 de marzo de 2020) $<$ https://www.lavanguardia.com/vida/20200329/48156331388/una-de-cada-tresempleadas-del-hogar-quedara-fuera-de-la-ayuda-extraordinaria.html> última consulta el 23 de noviembre de 2021.

93 Luigi Ferrajoli, Manifiesto por la igualdad (Trotta, 2019) 204.
} 
Por otro lado, en materia laboral y de seguridad social se realizaron varias propuestas que pueden simplificarse en una sola: la equiparación de derechos y garantías de las trabajadoras del hogar con las reconocidas a personas empleadas en otros ámbitos laborales. Seguidamente se exponen algunas de las medidas de despliegue de esta propuesta.

Como medida prioritaria, las trabajadoras han insistido en la inclusión total y sin excepciones del Sistema Especial para Empleados de Hogar en el RGSS. Como se ha expuesto, las promesas relativas a esa integración vienen posponiéndose desde hace nueve años y, según las últimas disposiciones al respecto, las trabajadoras deberían esperar hasta el 2023. Además, se señaló que el derecho al paro podría reconocerse por el simple procedimiento de incluir esta cuestión en los Presupuestos Generales del Estado para el año siguiente; exigencia que, una vez más, fue desoída:

El proyecto [de Presupuestos del Estado] tampoco prevé reconocer en 2021 la prestación de desempleo para el sector. La situación actual de incertidumbre para la clase trabajadora [...] está siendo crítica. Esta política es especialmente discriminatoria y afecta en su gran mayoría solo a mujeres. La experiencia del subsidio extraordinario sirve para tener claro que el objetivo no puede ser otro que la igualdad de derechos, sin excepciones. ${ }^{94}$

En cuanto la prevención de riesgos laborales, se sostuvo que legislar sobre la materia constituye una cuestión fundamental, sobre todo en la coyuntura pandémica actual. El vacío legal que existe está vulnerando el derecho a la salud de las trabajadoras, en evidente contradicción con lo establecido por el artículo 13 del Convenio 189 de la OIT referente a la adopción de medidas para garantizar la seguridad y la salud en el trabajo.

Por otro lado, las mujeres que trabajan atendiendo a personas en situación de dependencia plantearon la necesidad de una regulación específica para ese sector, 95 ya que la actividad que realizan exige de cualificación sociosanitaria y conlleva responsabilidades mayores. En este marco, se señaló que la problemática de la dependencia debe ser tomada en serio por la clase política; que se trata de una cuestión que ya no resiste ser invisibilizada dado el elevado envejecimiento de la población.

Específicamente, se sostuvo que los organismos estatales deberían realizar campañas de concienciación, ya que es

\footnotetext{
94 'Pagad ya el subsidio extraordinario para las trabajadoras de hogar; incluid en los presupuestos de 2021 la prestación por desempleo' (Grupo de Acción Política, 06 de noviembre de 2020) <https://sindillar.org/comunicado-30-de-marzo-diainternacional-de-las-trabajadoras-de-hogar/> última consulta el 23 noviembre de 2021.

95 Esta postura no es compartida por otros grupos de trabajadoras, quienes sostienen que la regulación en el empleo de hogar debe ser común, aunque sí aceptan la importancia de establecer diferentes categorías de actividades dentro de la regulación del sector.
} 
imprescindible que la sociedad en general y las familias en particular entiendan las problemáticas derivadas de la dependencia, así como la complejidad que reviste el trabajo que realizan las cuidadoras.

Estas demandas se fundamentan en el hecho de que muchas veces la parte empleadora desconoce la gravedad de la incapacidad y/o las precauciones que la misma requiere, y la trabajadora termina por asumir cargas inhumanas. Para ejemplificar, si una persona padece de un tercer grado de dependencia, ${ }^{96}$ se debería requerir la atención de dos trabajadoras como mínimo; de lo contrario, la cuidadora estaría activa las 24 horas del día (como de hecho sucede en muchos casos).

Respecto al Convenio 189 de la OIT, las trabajadoras señalaron que los cambios requeridos se deben producir de manera urgente, con independencia de la ratificación del mismo. Es decir, si bien el convenio establece un marco de actuación y es importante que España lo ratifique, el reconocimiento de derechos y garantías a nivel estatal no puede estar supeditado a que ello ocurra. En un documento final que recoge las conclusiones del encuentro, las trabajadoras exponen que:

En relación a la ratificación del C189, se planteó que los derechos pendientes en materia de Seguridad Social y prevención de riesgos laborales, así como la realización efectiva de todos los derechos ya reconocidos formalmente en la legislación española, no pueden esperar a la ratificación del Convenio. Los exigimos ya, y no admitimos que la ratificación pendiente atrase el reconocimiento de la igualdad de derechos. El lema que recogería esta idea es: «Todos los derechos para todas las trabajadoras, y además el C189». ${ }^{97}$

$Y$ es que, en efecto, existiendo una voluntad política declarada de ratificar ese instrumento internacional, y no siendo esto necesario para homologar la situación laboral de las trabajadoras del hogar -al bastar, como se ha tratado de mostrar, una serie de reformas legales capilares-, el argumento formal del proceso internacional en curso no parece revestir el suficiente peso para seguir postergando una vindicación tan elemental.

\section{6.- CONSIDERACIONES FINALES}

En una época en que la agenda política pública ha situado en primera línea discursiva el combate contra las desigualdades de género, resulta imperdonable que todavía existan enormes sectores de

\footnotetext{
96 La Ley 39/2006, de 14 de diciembre, de Promoción de la Autonomía Personal y Atención a las personas en situación de dependencia de España, en su artículo 26.1 establece: «Grado III. Gran dependencia: cuando la persona necesita ayuda para realizar varias actividades básicas de la vida diaria varias veces al día y, por su pérdida total de autonomía física, mental, intelectual o sensorial, necesita el apoyo indispensable y continuo de otra persona o tiene necesidades de apoyo generalizado para su autonomía personal».

97 'Encuentro Estatal de Acción Política Trabajadoras del Hogar y de los Cuidados' (Grupo de Acción Política, 18 de octubre de 2020) <https://sindillar.org/comunicado30-de-marzo-dia-internacional-de-las-trabajadoras-de-hogar/> última consulta el 23 de noviembre de 2021.
} 
mujeres visiblemente marginadas y vulneradas por las mismas leyes que dicen protegerlas.

En este contexto, la normativa sobre extranjería y la relativa a la actividad laboral en cuestión, en lugar de apaciguar unas relaciones embebidas por el machismo, el racismo y el clasismo, termina por reforzarlas. La discriminación es evidente. En un escenario de segregación laboral, donde las mujeres migrantes ocupan un sector históricamente precarizado, la única manera viable para regularizar la situación administrativa pasa por una oferta laboral materialmete dificultosa, en un país con una tasa de paro general del 15,26\%, cifra que aumenta en más de dos puntos entre las mujeres. ${ }^{98}$ De otro lado, la normativa laboral y de seguridad social presenta lagunas notorias, y los derechos sí reconocidos no se respetan por falta de garantías y, por supuesto, a causa de una débil voluntad política en ese sentido.

La pandemia del COVID-19 ha dejado al descubierto la precariedad de las trabajadoras del hogar: muchas mujeres se vieron obligadas a continuar trabajando, incluso confinadas en los domicilios de sus empleadores; muchas otras fueron despedidas, en el mejor de los casos con una indemnización irrisoria y sin derecho a la prestación por desempleo. Mientras tanto, las trabajadoras siguen esperando ser incluidas en el ámbito de aplicación de la Ley de prevención de riesgos laborales y la integración total del sector en el RGSS.

Para revertir esta situación, a todas luces discriminatoria, es imprescindible que las normativas cambien y que se articulen los mecanismos pertinentes para garantizar un trabajo en condiciones dignas. Pero, como ha señalado Capella, los derechos y los deberes jurídicos respectivos tienen un coste económico, y esta es la razón por la cual muchas veces no se establecen los medios para garantizarlos de manera efectiva, quedando el derecho reconocido vacío o semivacío. ${ }^{99}$

En el caso de las trabajadoras del hogar ese coste económico viene dado por partida doble: por un lado, los gastos relativos a las medidas directamente vinculadas con la protección social y laboral de las trabajadoras; por otro, aquellos relacionados con la dependencia. Como ha sostenido Otxoa, «El empleo de hogar es una vía de ahorro para familias y para el presupuesto de gasto social». ${ }^{100}$ Es importante subrayar esta realidad: las trabajadoras del hogar, sobre todo las sin papeles, están sosteniendo hoy un coste que el Estado no quiere

98 'Tasas de paro por distintos grupos de edad, sexo y comunidad autónoma' (Instituto Nacional de Estadística, 2021) <https://www.ine.es/jaxiT3/Tabla.htm?t=4247> última consulta el 23 de noviembre de 2021.

99 Juan Ramón Capella, 'Derechos, deberes: La cuestión del método de análisis' en José A. Estévez Araújo (ed) El libro de los deberes. Las debilidades e insuficiencias de la estrategia de los derechos (Trotta, 2013) 47.

100 Isabel Otxoa, 'Sin novedad en el empleo de hogar' (Viento Sur, 29 de octubre de 2020) <https://vientosur.info/sin-novedad-en-el-empleo-de-hogar/> última consulta el 23 de noviembre de 2021. 
asumir, y sin ellas la falta de respuestas estatales en materia de dependencia quedaría demasiado a la vista, volviéndose el problema contra el aparato institucional. En este sentido, la falta de derechos y garantías laborales y las restricciones en materia de extranjería resultan dos caras de la misma moneda.

Al respecto, se ha sostenido que la experiencia del contrato privado de empleo del hogar ha demostrado que éste no puede garantizar los derechos de las trabajadoras, y que por ello la solución a largo plazo estaría en desplazar la gestión de los servicios de cuidados a la administración pública. ${ }^{101}$ Mientras tanto, se presenta como una urgencia la inclusión total del sector en el RGSS y la planificación de fórmulas para posibilitar un mayor control de la actividad.

Asimismo, se considera imprescindible la reforma de la normativa sobre extranjería. En una época en que la globalización no reglada ha incrementado de manera exponencial las desigualdades, llegando a conformar un apartheid mundial, 102 parece inadmisible continuar con el actual hermetismo de las políticas migratorias. En este sentido, se insiste en la necesaria complementariedad de las modificaciones normativas tanto en materia laboral como en materia de extranjería; puesto que, si solo se considerara el extremo relativo a la actividad laboral, miles de mujeres sin papeles quedarían excluidas de los derechos eventualmente conquistados.

Por último, es importante señalar que las trabajadoras, en tanto personas con capacidad de agencia, deben estar incluidas en la planificación e implementación de las políticas que las afectan. Nadie más que ellas conoce la situación y las necesidades del sector.

Mientras las reformas continúan suspendidas y los derechos vacíos, las trabajadoras del hogar seguirán organizándose de manera colectiva, generando espacios de cuidados mutuos y luchando para que sus demandas sean escuchadas.

\section{7.- BIBLIOGRAFÍA}

\section{1.- Jurisprudencia}

Sentencia 13/2001 (2001) AN Sala de lo contencioso-administrativo. Sentencia 1184/2021 (2021) TS Sala de lo contencioso-administrativo.

\section{2.- Legislación}

Constitución Española.

Ley Orgánica 3/2007, de 22 de marzo, para la igualdad efectiva de mujeres y hombres.

101 Ibid.

102 Luigi Ferrajoli, Manifiesto por la igualdad, p. 206 (Trotta, 2019). 
La Ley Orgánica 4/2000, de 11 de enero, sobre derechos y libertades de los extranjeros en España y su integración social.

Ley Orgánica 4/2015, de 30 de marzo, de protección de la seguridad ciudadana.

Ley Orgánica 11/1985, de 2 de agosto, de Libertad Sindical.

Ley 27/2011, de 1 de agosto, sobre actualización, adecuación y modernización del sistema de Seguridad Social.

Ley 39/2006, de 14 de diciembre, de Promoción de la Autonomía Personal y Atención a las personas en situación de dependencia de España.

Real Decreto-ley 29/2012, de 28 de diciembre, de mejora de gestión y protección social en el Sistema Especial para Empleados de Hogar y otras medidas de carácter económico y social.

Real Decreto-ley 13/2020, de 7 de abril, por el que se adoptan determinadas medidas urgentes en materia de empleo agrario.

Real Decreto Legislativo 2/2015, de 23 de octubre, por el que se aprueba el texto refundido de la Ley del Estatuto de los Trabajadores.

Real Decreto 1424/1985, de 1 de agosto, por el que se regula la relación laboral de carácter especial del Servicio del Hogar Familiar.

Real Decreto 1620/2011, de 14 de noviembre, por el que se regula la relación laboral especial del servicio del hogar familiar.

Real Decreto 557/2011, de 20 de abril, por el que se aprueba el Reglamento de la Ley Orgánica 4/2000, sobre derechos y libertades de los extranjeros en España y su integración social, tras su reforma por Ley Orgánica 2/2009.

Decret llei 25/2020, de 16 de juny, de mesures extraordinàries en matèria social i de caràcter fiscal i administratiu.

\section{3.- Otras fuentes}

\subsection{1.- Libros}

Arella C y otros, Una aproximación a la vulneración de los derechos humanos de las trabajadoras sexuales en la ciudad de Barcelona (Universidad de Barcelona, Observatori del Sistema Penal i els Drets Humans 2006).

Estévez Araújo J (ed) El libro de los deberes. Las debilidades e insuficiencias de la estrategia de los derechos (Trotta 2013).

Ferrajoli L, Manifiesto por la igualdad (Trotta 2019).

Ferrajoli L, Derechos y garantías. La ley del más débil (Trotta 2004).

Laboratorio Feminista (ed) Transformaciones del trabajo desde una perspectiva feminista. Producción, reproducción, deseo, consumo (Tierradenadie 2006).

Osorio Pérez V (ed) De cuidados y descuidos. La economía del cuidado en Colombia y perspectivas de política pública (Escuela Nacional Sindical 2015). 
Pateman C, El contrato sexual (Anthropos 1995).

Pérez Orozco A, Subversión feminista de la economía. Aportes para un debate sobre el conflicto capital-vida (Traficantes de sueños 2019).

Pérez Orozco A, Perspectivas feministas en torno a la economía: el caso de los cuidados (Consejo Económico y Social 2006).

Pérez Orozco A y López Gil S, Desigualdades a flor de piel: Cadenas globales de cuidados (ONU mujeres 2011).

Rodríguez E, El gobierno imposible. Trabajo y fronteras en las metrópolis de la abundancia (Traficantes de Sueños 2003).

Silveira H (ed) Identidades comunitarias y democracia (Trotta 2000).

Zarauz J, Incidencia del padrón municipal en el ejercicio de los derechos de las personas extranjeras en situación irregular (Colección de Derechos Humanos Padre Francisco de Vitoria 2007).

\subsection{2.- Artículos científicos}

Abasolo O, 'El debate feminista en torno al concepto de cuidados' (2010) 10 CIP-Ecosocial Boletín ECOS 1.

del Río S, 'La crisis de los cuidados: precariedad a flor de piel' (2004) CGT Comisión Confederal contra la Precariedad 1.

Ezquerra S, 'Crisis de los cuidados y crisis sistémica: la reproducción como pilar de la economía llamada real' (2011) 2 Investigaciones Feministas 175.

Juliano D, 'Género y trayectorias migratorias en época de crisis' (2012) 97/3 Papers 536.

Melero Alonso $\mathrm{E}$, 'Las identificaciones policiales con perfil racial o étnico como instrumento de control migratorio: derecho administrativo del enemigo' (2018) 193 Revista Española de Derecho Administrativo 243.

Mestre i Mestre R, 'Por qué las inmigrantes no trabajan. Breve crítica feminista al derecho de extranjería' (1999) 36 Jueces para la democracia 22.

Otxoa I, 'La nueva regulación de las trabajadoras del hogar' (2012) 12 Themis Revista jurídica de igualdad de género 34.

Rodríguez Ruiz B, 'Hacia un estado post-patriarcal. Feminismo y cuidadanía' (2010) 149 Revista de Estudios Políticos nueva época 87.

Rojo Torrecilla, E. 'Ampliación de la posibilidad de solicitar la autorización de residencia por arraigo laboral' (2021) 5/2021 Revista de Jurisprudencia Laboral 7.

Sanz Sáez C, 'Los derechos colectivos del trabajo doméstico con relación al Estatuto de los Trabajadores' (2021) 45 Lan Harremanak 138.

Silveira Gorski H, 'Biopolítica de Estados expulsores' (2012) 49 Política y Sociedad 497.

\subsection{3.- Fuentes web}


'Acuerdo Schengen' (Ministerio del Interior) $<$ http://www.interior.gob.es/web/servicios-alciudadano/extranjeria/acuerdo-de-schengen $>$ última consulta el 23 de noviembre de 2021.

'Afiliados a fin de mes, por edad, género, régimen y nacionalidad' (Tesorería General de la Seguridad Social, abril de 2021) <https://w6.seg-social.es/PXWeb/pxweb/es/> última consulta en abril de 2021.

'Barcelona facilitará el empadronamiento sin domicilio fijo a vecinos que carezcan de un hogar estable' (La Vanguardia, 2016) $<$ https://www.lavanguardia.com/local/barcelona/20161219/4127 32511652/barcelona-empadronamiento-sin-domiciliofijo.html\# : : text=El\%20Ayuntamiento\%20de\%20Barcelona\%20 ha,otras $\% 20$ circunstancias $\% 20$ de $\% 20$ vulnerabilidad\%20habitacio nal. > última consulta el 23 de noviembre de 2021.

'Catálogo completo de ocupaciones de difícil cobertura' (SEPE, 2021) $<$ https://www.sepe.es/HomeSepe/empresas/informacion-paraempresas/profesiones-de-dificil-cobertura/profesiones-masdemandadas.html> última consulta el 23 de noviembre de 2021.

'Encuentro Estatal de Acción Política Trabajadoras del Hogar y de los Cuidados' (Grupo de Acción Política, 18 de octubre de 2020) $<$ https://sindillar.org/comunicado-30-de-marzo-dia-internacionalde-las-trabajadoras-de-hogar/> última consulta el 23 de noviembre de 2021.

'Esperanza de vida al nacimiento según sexo' (Instituto Nacional de Estadísticas, 1975, 2019) <https://www.ine.es/jaxiT3/Tabla.htm?t=1414> última consulta el 7 de agosto de 2020.

'Estadística de autorizaciones de trabajo a extranjeros' (Subdirección Nacional de Estadística y Análisis Sociolaboral, mayo de 2021) <https://www.mites.gob.es/estadisticas/pte/welcome.htm> última consulta el 13 de junio de 2021.

'Estadísticas' (ATH-ELE, 2020) <https://ath-ele.com/es/estadisticas/> última consulta el 23 de noviembre de 2021.

Fulladosa Leal K, 'Mujeres en movimiento: ampliando los márgenes de participación social y política en la acción colectiva como trabajadoras del hogar y el cuidado' (Tesis Doctorals en Xarxa, 2020)

<https://www.tesisenred.net/handle/10803/455567\# page $=183>$ última consulta el 23 de noviembre de 2021.

González Fernández T, 'La discriminación múltiple de las trabajadoras sexuales extranjeras en España' (Dipòsit Digital de la Universitat de

Barcelona,

<http://diposit.ub.edu/dspace/handle/2445/1201> última consulta el 23 de noviembre de 2021.

'Número de hogares monoparentales según sexo, edad y estado civil del progenitor' (Instituto Nacional de Estadística, 2019) <https://www.ine.es/jaxi/Tabla.htm?path=/t20/p274/serie/prov/ 
p01/l0/\&file=01017.px\&L=0 > última consulta el 7 de agosto de 2020.

Otxoa I, 'Con y sin Convenio 189, todos los derechos para las trabajadoras del hogar' (Viento Sur, 27 de junio de 2018) <https://www.eldiario.es/opinion/tribuna-abierta/convenio-oitderechos-trabajadoras-hogar 129 2048596.html> última consulta el 23 de noviembre de 2021.

Otxoa I, 'Sigue el fraude de la Seguridad Social' (Viento Sur, 22 de febrero de 2020) <https://vientosur.info/sigue-el-fraude-de-laseguridad-social/> última consulta el 23 de noviembre de 2021.

Otxoa I, 'Sin novedad en el empleo de hogar' (Viento Sur, 29 de octubre de 2020) <https://vientosur.info/sin-novedad-en-elempleo-de-hogar/> última consulta el 23 de noviembre de 2021.

'Pagad ya el subsidio extraordinario para las trabajadoras de hogar; incluid en los presupuestos de 2021 la prestación por desempleo' (Grupo de Acción Política, 06 de noviembre de 2020) $<$ https://sindillar.org/comunicado-30-de-marzo-dia-internacionalde-las-trabajadoras-de-hogar/> última consulta el 23 de noviembre de 2021.

'Proporción de personas mayores de cierta edad' (Instituto Nacional de Estadísticas, 1975,

2020) $<$ https://www.ine.es/jaxiT3/Tabla.htm?t=1417\&L=0 > última consulta el 7 agosto de 2020.

'Respecto al Real Decreto-ley 13/2020, de 7 de abril, por el que se adoptan determinadas medidas urgentes en materia de empleo agrario' (Sindihogar, abril de 2020) $<$ https://sindillar.org/comunicado-30-de-marzo-dia-internacionalde-las-trabajadoras-de-hogar/> última consulta el 23 de noviembre de 2021.

'Tasas de actividad por distintos grupos de edad, sexo y comunidad autónoma' (Instituto Nacional de Estadística, 1980, 2020) <https://www.ine.es/jaxiT3/Tabla.htm?t=4206\&L=0> última consulta el 7 de agosto de 2020.

'Tasas de paro por distintos grupos de edad, sexo y comunidad autónoma' (Instituto Nacional de Estadística, 2021) $<$ https://www.ine.es/jaxiT3/Tabla.htm?t=4247> última consulta el 23 de noviembre de 2021.

'Una de cada tres empleadas del hogar quedará fuera de la ayuda extraordinaria' (La Vanguardia, 29 de marzo de 2020) <https://www.lavanguardia.com/vida/20200329/48156331388/u na-de-cada-tres-empleadas-del-hogar-quedara-fuera-de-laayuda-extraordinaria.html > última consulta el 23 de noviembre de 2021. 